This is the peer reviewed version of the following article: European Journal of Lipid Science and Technology, vol. 121, Iss. 8, 1800490 (2019), which has been published in final form at https://doi.org/10.1002/ejlt.201800490. This article may be used for non-commercial purposes in accordance with Wiley Terms and Conditions for Self-Archiving.

\title{
Effect of Pollution on the Quality of Olive Oils from Trees Grown Near a Phosphoric Acid Factory
}

Ons Rekik; Amir Ben Mansour; Hazem Jabeur; Guillermo Rodríguez Gutiérrez; Mohamed Bouaziz

\begin{abstract}
Given the importance of olive oil as a food product worldwide and given the exposure of many productive olive orchards to many pollution sources, this work is a contribution to the clarification of atmospheric metal pollution effects on the quality of olive oil and its possible toxicity for human beings. This work is carried out on olive orchards (Olea europaea L., cv. Chemlali) situated in a polluted region close to a fertilizer factory and in a controlled, unpolluted area, managed with comparable cultivation techniques during two successive years (2015/2016 and 2016/2017). Pollution negatively affects the oxidative stability and nutritional value of olive oil, especially by decreasing the contents of antioxidant compounds and the fatty acid composition. Atmospheric metals are confirmed to have a negative effect on olive oil chemicals; oils show a disruption of their squalene, tocopherols, and triglyceride composition in comparison with control oils.
\end{abstract}

Practical Applications: This study is carried out in two olive orchards (Olea europaea L., cv. Chemlali) located in a polluted area near a fertilizer factory and in a control unpolluted site, managed with similar cultivation techniques. The aim is to investigate the physiological and biochemical responses of polluted oils (PO), exposed to atmospheric metal contamination as compared to control oils ( $\mathrm{CO}$ ). The results of this study emanate from the accidental exposure to contamination sources, such as the direct contact of olives, with an elevated polluted environment that might be made more severe by gaseous air pollutants emitted by the factory. Then, air contamination avoidance from factories should be examined together with any possible probable methodologies to decrease plant tissue contamination.

\section{Introduction}

The features of city air pollution have changed significantly over the past decades. The Concentrations of traditionally important pollutants, as Sulphur dioxide (SO2) and black smoke 
have declined substantially, whilst factories emissions have been considered as the most significant factor of the quality poor air.1

Nowadays, in Tunisia, owing to the rigorous proliferation of the industrial productions, the olive cultivation, among the essential agricultural activities in the country, is encountering a combination of arid climate and air pollution effects. Sfax city, this accommodates one of the major industrial complexes in Tunisia. It is subjected to severe chronic airborne pollutants, including fluoride compounds emitted by a phosphate fertilizer. In fact, the Industrial Society of Phosphoric Acid and Fertilizers (SIAPE), is considered as the major source of pollution in Sfax. It has confirmed to have a harmful effect on the landscape around it, thus causing a gradual degradation in the surrounding vegetation.

SIAPE, which is a factory producing phosphate fertilizer, is situated in the southern suburb of Sfax. It transforms crude phosphate with an elevated fluoroapatite [Ca5(PO4)3F] content into a granule phosphate fertilizer smoothing absorbed by plants. Indeed, metals, namely $\mathrm{Cd}, \mathrm{Cu}, \mathrm{Fe}$, $\mathrm{Mn}, \mathrm{Ni}, \mathrm{Pb}$, and $\mathrm{Zn}$ are released from the industry chimney, during the phosphate attack by sulphuric and phosphoric acids, in the form of inorganic particulate.2, 3

The environmental checking around the industrial settings has been done over the years by many researchers to shed the light on the pollution created by the industries and the harmful effects of the pollutants on the community health. Besides, it permits to prevent the occupational hazards. Previous research has recently revealed that at high concentrations, many of the pollutants present in exhaust gases can be damaging to plants.3-6 Much of this research has, however, investigated uniquely the individual components of exhaust emissions and, to the best of our knowledge, very little research work has been undertaken on the influence of the specific combination of pollutants characterizing urban regions. Therefore, vegetation developed around the SIAPE Society is continuously exposed to air metal pollution and are referred to as polluted olive oil (POO). On the other hand, the control plot (with control oil, $\mathrm{CO}$ ) was located in Menzel Chaker region in Sfax, $45 \mathrm{~km}$ north of SIAPE, in an inland rural area, without any industries. To determine the impact of pollution on the quality of oil, the obtained values of each parameter were compared with those of control oil samples.

\section{Experimental Section}

\subsection{Samples}

Olive oils were obtained from Unwashed and washed olive fruits (Olea europaea L.cv. Chemlali) manually picked in olive groves situated in a land plot at $0.7 \mathrm{~km}$ from the SIAPE, are referred to as "polluted oils," PO. However, the control plot (with control olive oils, COO) was located in Menzel Chaker region, $45 \mathrm{~km}$ west of the "SIAPE," in an inland rural area, without any industries. Sampling was conducted during two consecutive crops (2015/2016 and 2016/2017).

For each sample, about $2 \mathrm{~kg}$ of fresh olives that were handpicked were used for olive oil production. Each sample from "PO" was divided into two portions, one of which was washed and rinsed with deionized water and referred to as "Washed Polluted Oils, WPO," and the other one was referred to as "Unwashed polluted oils, UWPO." Cold extractions were realized 
in laboratory by oleodoseur system (composed of crusher, vertical malaxator, and centrifuge). Then, the produced oils were filled in dark bottles and conserved for analysis at $4{ }^{\circ} \mathrm{C}$.

\subsection{Analytical Methods}

\subsubsection{Fatty Acid Methyl Ester Analysis}

Olive oil in n-heptane $(0.12 \mathrm{~g}$ per $2 \mathrm{~mL}$ ) was transmethylated using a cold solution of $\mathrm{KOH}$ (2mol L-1) $(200 \mu \mathrm{L})$ according to the European Standard NF EN ISO 5509 Norm.7 Fatty acid methyl esters (FAMEs) were analyzed according to the European Standard NF EN ISO 5508 Norm. 8 The gas chromatographic analysis of FAMEs was performed on an Auto System Gas chromatograph equipped with a FID detector (HP 6890 N; Agilent Technologies, J\&W Scientific Products, Palo Alto, PA, USA). The column used was a capillary Agilent CP-Sil88 (length $50 \mathrm{~m}$, id $0.25 \mathrm{~mm}$ and film thickness $0.20 \mu \mathrm{m}$ ), and the analysis conditions were as follows: the column temperature was programmed first at $165^{\circ} \mathrm{C}$ for $25 \mathrm{~min}$ and second at a gradient of $5^{\circ} \mathrm{C} \mathrm{min}-1$ up to $195^{\circ} \mathrm{C}$. Injector and detector temperature was set at $250^{\circ} \mathrm{C}$, helium was the carrier gas, with a flow through the column of $1 \mathrm{~mL} \mathrm{min-1}$ and 1:100 split ratio, and the injection volume was $1 \mu \mathrm{L}$. The identification of the fatty acids was realized by comparing of the retention time with those of olive oil fatty acids, whose composition is known. The determination of fatty acid percentages was conducted by internal standardization without considering mass response factors.9, 10 As for the determination of FAMEs, it was conducted by comparing their retention times with pure standards analyzed under the same conditions. They quantification was performed according to their percentage area, obtained by the integration of the peaks. The results were expressed as the percentages of individual fatty acids in the lipid fraction. The variation coefficients were inferior to $5 \%$ for the major FAMEs and lower than $10 \%$ for some trivial ones. Squalene, whose peak is well detached from that of $\mathrm{C} 24: 0$, was determined along with the fatty acids by an external standard calibration curve, as given in Equation 1:

$A=248.36 \mathrm{C}-0.79$

where $A$ is the peak area of squalene, and $C$ is the concentration expressed in $m g m L-1$ ) (linearity: 0.030 to $0.60 \mathrm{mg} \mathrm{mL}-1, \mathrm{R} 2=0.999$ ). The calculation of final results on the basis of the analyzed oil weight, were expressed in $\mathrm{mg} \mathrm{kg}-1$ with a variation coefficient equal to $1.2 \%$ according to the experimental error.

The fatty acids of olive oil were identified by comparing of their retention time, whose composition is known. The determination of fatty acid percentages was realized by internal standardization without considering mass response factors.10 The coefficients of variation were lower than $5 \%$ for the major FAMEs and lesser than $10 \%$ for some minor ones.

\subsubsection{Nomenclature of Fatty Acids}

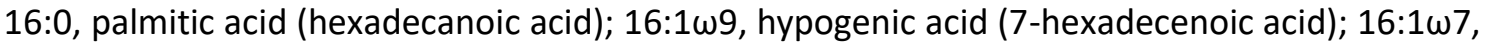

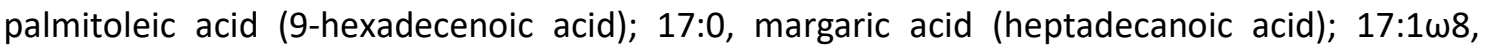
margaroleic acid, 18:0, stearic acid, (9-heptadecenoic acid); 18:1 $\omega 9$, oleic acid (9-octadecenoic

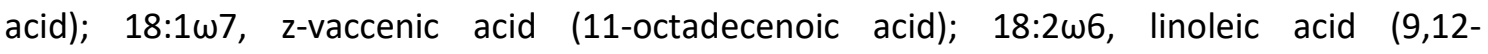


octadecadienoic acid); 18:3w3, linolenic acid (9,12,15-octadecatrienoic acid); 20:0, arachidic

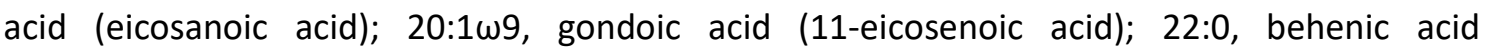
(docosanoic acid); 24:0, lignoceric acid (tetracosanoic acid).

\subsubsection{Triacylglycerol Determination}

TAG molecular species of olive oil were separated by HPLC equipped with a RP C-18 column $(4.6 * 250 \mathrm{~mm}$, particle size $5 \mathrm{~mm}$, Shimadzu, Kyoto, Japan). The eluant was monitored by refractive index detector (model RID-10Avp, Schimadzu). The mobile phase was acetone/acetonitrile $(60: 40, \mathrm{v} / \mathrm{v})$ with a flow rate of $1.50 \mathrm{~mL} \mathrm{~min}-1$. All solvents were of HPLC grade. Samples $(5 \mathrm{~mL})$ were prepared by dissolving the oil in acetone $(9: 91, \mathrm{v} / \mathrm{v})$. The volume of injection was $10 \mathrm{~mL}$. The assumption was that the sum of the areas of the peaks that correspond to the various TGs was equal to $100 \%$, and the relative percentage of each TG was calculated.11 The TAGs in olive oils were separated according to the equivalent carbon number (ECN), defined as $\mathrm{CN}-2 \mathrm{n}$, where $\mathrm{CN}$ is the total acyl carbon number and $\mathrm{n}$ is the number of double bonds of fatty acids.12 Each analysis was duplicated, and the mean percentages were used. The percentages of various compounds were obtained by internal normalization without take into consideration of the weight response factors.

\subsubsection{Tocopherols Content}

HPLC analysis for $\alpha$-tocopherol was performed with an Agilent (1100) Series HPLC system chromatograph (Hewlett Packard, Waldbronn, Germany) apparatus. Detection was carried out at $290 \mathrm{~nm}$ for $\alpha$-tocopherol according to the method of European Standard.13 The column was (C-18, $4.6250 \mathrm{~mm}$, particle size $5 \mathrm{~mm}$, shim-pack, VP-ODS, Shimadzu, Kyoto, Japan). The used elution solvents were A ( $2 \%$ acetic acid in water), B (methanol), C (acetonitrile), and D (isopropanol). The elution of the samples was made according to the gradient that follows: $95 \% \mathrm{~A} / 5 \% \mathrm{~B}$ in $2 \mathrm{~min} ; 60 \% \mathrm{~A} / 10 \% \mathrm{~B} / 30 \% \mathrm{C}$ in $8 \mathrm{~min} ; 25 \% \mathrm{~B} / 75 \% \mathrm{C}$ in $22 \mathrm{~min}$. Besides, this percentage was kept for $10 \mathrm{~min} ; 40 \% \mathrm{C} / 60 \% \mathrm{D}$ in $10 \mathrm{~min}$; for $15 \mathrm{~min} ; 25 \% \mathrm{~B} / 75 \% \mathrm{C}$ in $2 \mathrm{~min}$, and finally, $95 \% A / 5 \% B$ in $3 \mathrm{~min}$. Flow rate was $1 \mathrm{~mL} \mathrm{~min}-1$ and run time was $70 \mathrm{~min}$. The run was conducted at $328^{\circ} \mathrm{C}$. The sample injection volume was $20 \mathrm{~mL}$. The Identification of $\alpha-$ tocopherol was achieved by comparing its retention time values with its standard.14 The determination of $\alpha$-tocopherol content was realized by diluting approximately $1100 \mathrm{mg}$ of olive oil in $1 \mathrm{~mL} n$-hexane mixture and analyzing the sample solution by HPLC. The Concentrations of $\alpha$-tocopherol contents were then calculated from the integrated samples peak areas of the samples and the calibration curve of $\alpha$-tocopherol standard. Good linearity was achieved in the range $300-1100 \mathrm{mg} \mathrm{kg}-1$ ( $y=1.30 x, \mathrm{r} 2=0.899)$.

\subsubsection{HPLC Analysis of Polar Phenolic Compounds}

The phenolic compounds were analyzed using an Agilent Technologies series 1100 liquid chromatography system (HPLC, Agilent Technologies, and Karlsruhe, Germany) equipped with an automatic injector, made up of a vacuum degasser, quaternary pump, a column oven and a diode array detector (DAD). An Eclipse XDB-C18 column $(250 \times 4.6 \mathrm{~mm}$, i.d., $5 \mu \mathrm{m}$ particle size; Waters Co., Milford, MA) was utilized and kept at ambient temperature $\left(25^{\circ} \mathrm{C}\right)$ with an injection volume of $10 \mu \mathrm{L}$ and a flow rate of $0.8 \mathrm{~mL} \mathrm{~min}-1$. The mobile phase comprised of $0.25 \%$ acetic acid in water (solvent A)/methanol (solvent B) at a flow rate of $0.8 \mathrm{~mL} \mathrm{~min}-1$, 
with the steps that follow: $0 \mathrm{~min}, 5 \% \mathrm{~B} ; 7 \mathrm{~min}, 35 \% \mathrm{~B} ; 12 \mathrm{~min}, 45 \% \mathrm{~B} ; 17 \mathrm{~min}, 50 \% \mathrm{~B} ; 22 \mathrm{~min}$, $60 \% \mathrm{~B} ; 25 \mathrm{~min}, 95 \% \mathrm{~B} ; 27 \mathrm{~min}, 5 \% \mathrm{~B}$. Then a conditioning cycle of $5 \mathrm{~min}$ at comparable conditions for the subsequent analysis.15

The phenolic compounds were quantified by using as external standards the reference compounds obtained from commercial suppliers: Tyrosol was obtained from Fluka (Buchs, Switzerland), oleuropein, ligtrosid, and hydroxytyrosol were obtained from Extrasynthese (Lyon Nord, Geney, France). The quantitative evaluation of phenolic compounds was based on a comparison of the retention times with that of the reference compounds and recording the UV spectra in the range of $200-360 \mathrm{~nm}$. The quantification was performed by means of a fivepoint regression curve in triplicate of individual stock solutions ( $R 2 \geq 0.99)$. The LOD and the LOQ were 40 and $50 \mathrm{ng} \mathrm{mL-1}$ respectively. The percentage recovery values of the standard used is only for internal standards; in this study only external ones were used.

\subsection{Determination of Metals}

Metal extraction from fruit surface was carried out on olive oil obtained from washed and unwashed polluted fruits. The oil was treated as follow; $5 \mathrm{~g}$ of oil are weighed in nickel crucibles. The mixture was calcined in an electric furnace at $500^{\circ} \mathrm{C}$ for $3 \mathrm{~h}$. The sample in the form of ash is mineralized by being wet in the presence of $10 \mathrm{~mL}$ of nitric acid HNO3 (1N). The contents are filtered in a volumetric flask of $100 \mathrm{~mL}$. It returns the contents to the mark with distilled water. A blank sample $(7 \mathrm{~mL}$ HNO3) was prepared following the same procedures used for oil samples. The total $\mathrm{Cd}, \mathrm{Cu}, \mathrm{Fe}$, and $\mathrm{Zn}$ concentrations were determined by inductively coupled plasma-atomic emission spectrometry (ICP-AES; Thermo iCAP 6000 series, Thermo Fisher Scientific Inc., Waltham, MA). The emission wavelengths selected for element quantification were: Cd 228.8 nm; Cu 324.7 nm; Fe 259.9 nm; Zn 206.2 nm.

\subsection{Statistical Analysis}

The obtained results were expressed as the mean \pm standard deviation (SD) of three measurements for the analytical determination. The significant differences between the values of all parameters were identified at $p<0.05$ following the one-way ANOVA: Student NewmanKeuls test by means of SPSS Statistics 17.0 for Windows (SPSS Inc., 2008).

The aim of applying non-standardized principal component analysis (PCA) was to demonstrate the effect of all investigated parameters $(n=50)$ on the olive oils samples using the Varimax rotation together with Kaiser Normalization. The PCA type was Pearson ( $n$ ), the biplot type was correlation biplot and the coefficient was automatic. A uniform hierarchical cluster analysis (HCA) methodology was applied on data. Each cluster was determined by the following parameters: Similarity, Euclidean distance matrix and the Ward's method, generating a dendrogram for olive oil samples. All the chemometric analyses were carried out using XLSTAT software for Windows (v.2013.2.03, Addinsoft, New York, USA).

\section{Results and Discussion}

\subsection{Quality Indices}


Analytical parameters considered in this work (Table 1 ) of all samples to identify the oil category, Chemlali olive oils are listed in Table 1. The latter shows that no significant differences exist in the quality parameters between samples, so oils could be labeled as "extra virgin olive oil." 16

This result was estimated given the fact that the oils were obtained from handpicked fresh olives and without storage time before the extraction. As actually, the quality criteria rely basically upon the olive quality before the extraction and the storage oil conditions.17

\subsection{Chlorophyll and Carotenoid Contents}

Chlorophylls and carotenoids are the main pigments in vegetable oils. In olive oils, they play an essential role in the oxidative stability given prooxidant activity in the light and antioxidant nature in the dark. Furthermore, they are mainly responsible for the olive oil color, which varies from yellow-green to greenish gold.18 Moreover, pigments are involved in autoxidation and photooxidation mechanisms.19-21 The growing area conditions had a significant effect on the amount of pigments, the chlorophyll and carotenoids values in COO were generally higher than those found in PO, and this difference was more marked for chlorophyll (Table 1). The highest pigment content was discovered in the year of 2016, probably with the higher necessity for photo-protectant pigments against adverse arid climatic conditions is higher. For oils under study, chlorophylls were found at average concentrations between 3.58 and $16.96 \mathrm{ppm}$, while carotenes average concentration varied between one and $8.88 \mathrm{ppm}$ (Table 1). Chemlali olive oils from unwashed olives contained the lowest level of carotenoids while Chemlali olive oil from washed olives oil contained the highest level of carotenoid pigments $4.95 \mathrm{mg} \mathrm{kg}-1$.

These results are in agreement with the findings of other authors, 19 who reported that the atmospheric metals affected olive oil chemical negatively by the lesser values of pigments in leaves and fruits, as compared to control plants. The detected plant biochemical response advocates that polluted plants were not able to face the metal stress, which is proven by a drop of photosynthetic (chlorophyll), photo-protectant, and free-radical scavenging pigments (carotenoids), as pigments synthesis in polluted plants did not match their own degradation.

\subsection{Fatty Acid Composition}

The fatty acid composition has a fairly wide range due to genetic and environmental factors. It has earlier been used as a parameter for oil classification.10, 14 The average fatty acid composition expressed as percentage of total methyl esters is reported in Table 2. For all the samples, 14 fatty acids were detected and quantified.

Oleic (18:1n-9), palmitic (16:0), linoleic (18:2n-6), and stearic acids (18:0) were the main fatty acids identified in all the olive oils, the 10 other fatty acids were detected in low percentages (Table 2). Oleic acid is the main monounsaturated fatty acid in olives, and it is present in higher concentrations (50.15-60.22\%) than other acids. Palmitic acid content, the main saturated FA of olive oil, varies between $12.96 \%$ and $20.50 \%$ according to the zones of plantation. Polyunsaturated fatty acids are very important for human nutrition, as they are deemed 
essential. Linoleic acid was the dominant polyunsaturated fatty acid ranging from 17.44 to $19.45 \%$, while linolenic acid (Cl8:3) ranged from 0.49 to $1.2 \%$.

Variations in oleic and linoleic acid contents were observed in olive oil samples obtained from polluted olive oil, compared to the control olive oil, they are probably associated with both genetic factors and environmental conditions during the development and the fruit maturity. 20 The obtained results accord well with the findings of other authors, 21 who have revealed that many agronomic parameters can alter the fatty acid composition of olive oil. The aspects that are mostly studied comprise cultivar and origin, fruit ripening, harvest period, and pedoclimatic conditions of production.

\subsection{Squalene Content}

Squalene may contain up to $90 \%$ of the hydrocarbon fraction of olive oil. It is a natural antioxidant in the non-saponifiable fraction of $\mathrm{VOO}$, and exogenously administered in the diet, it reinforces the endogenous antioxidant system against oxidative damage.22 Squalene level varies with variety, origin, and extraction system. 23 The used analytical procedure for the determination of squalene allows for a quick comparison of squalene amounts in the samples (PO) studied with control olive oil (COO). The highest mean levels of squalene were observed with washed olives (1123.39 g kg-1) in 2015 and (1050.9 g kg-1) in 2016. Nevertheless, the lowest average contents of squalene were noticed in unwashed olives (845.39 g kg-1) for 2016 and $(985.21 \mathrm{~g} \mathrm{~kg}-1)$ for 2015 . The obtained results are lower than those found for control olive oil (1862.01 g kg-1) for 2016 and $1902.28 \mathrm{~g} \mathrm{~kg}-1)$ for 2015. The authors came to the conclusion that the reduction of squalene concentration in the oil emanated only from the participation of squalene in the biosynthesis of other compounds as sterols and triterpenes.24 However, the dynamics of oil accumulation was not investigated and therefore, the total amount of squalene present in the fruits was not characterized. It is noteworthy to consider that the squalene concentration in the oil depends on both the squalene content in the fruit and oil content in the fruit, that is, squalene content in the oil is the result of two different biosynthetic pathways. Furthermore, the squalene content in olive oil hinges on the extraction technology. 25

\subsection{Triacylglycerol Composition}

Table 3 displays the composition of triglycerides (TAG) expressed as the equivalent carbon number (ECN) found in olive oil of the Chemlali cultivar and investigated by different processing systems are displayed in Table 3. Nineteen triglycerides were identified (LLL; PLLn; OLLn + PoLL; OLL; OOLn; PLL; POLn; LOO + PLnP; PoOO. PLO + SLL; PoOP; PLP; OOO; SOL; POO; POP, SOO, POS; POA). The main molecular species of TAG in the olive oil sample were OOO, LOO + PLnP; POO; PLO + SLL, OLL, as expected from the high oleic acid and low linoleic and linolenic acid contents. These accounted for more than $70 \%$ of the total detected TAG, which is in agreement with the reported research works of Ammar et al.26 Afterwards, the level of triolein (OOO) and POO, the main TAG in control olive oil, was remarkably high, with concentrations of 19.98 and $22.06 \%$ for WPO 2016. Nonetheless, oil obtained from the unwashed polluted olives for 2015 had the lowest level with concentrations $16.21 \%$ and $18.50 \%$. In addition, the oil obtained from polluted olives had the lowest level of trilinolein LLL 
$(<0.5 \%)$. The presence of high triolein (OOO) level in proportion to trilinolein (LLL) represents an indicator of favorable authenticity indicator as described by ref. 27.

The two second TAG in the order of qualitative importance in the Chemlali olive oil corresponds to the $\mathrm{OOL}+\mathrm{PPLn}$ and $\mathrm{OLP}+\mathrm{SLL}$ contents, where the reported mean content ranged from 12.28 to $16.59 \%$. The next four TAG fractions are OLL, OOLn, PoOP+ PPL, and POP, whose content is similar for olive oil resulting from polluted olives. The last main molecular species is OOS, which is the most significant although its low content varied from 0 to $3 \%$ for the polluted olive oils.

\subsection{Total Phenols}

The phenolic compounds present in olive oils represent one of the vital elements of the nutritional importance and shelf life of this oil. Phenolic substances contribute to oil flavor and aroma and to the typical bitter taste of olive oil.28 The WPO preserves the phenolic content more than the UWPO, whose total phenol content varies from 162 to $170 \mathrm{mg} \mathrm{kg}-1$, for the year of 2015 and 2016, respectively. However, olive oils obtained from polluted olive fruits provided the lowest phenol contents compared with control olive oils. In addition, the phenols content of the oils samples were higher in the 2016 seasons (Table 1). This was possibly due to the effect of climatic conditions, which agrees well with the literature.29 Several works have shown that many factors as environmental and agronomic factors have impact on plant physiological behavior and, consequently, on oil chemical properties. 30

\subsection{Phenolic Compounds Content}

The amount of phenolic compounds in olive oil is an important factor for assessing its quality to enhance its resistance to oxidation. To some extent, it is responsible for its sharp bitter taste.31, 32 The analysis of phenolic substances using HPLC allowed the separation and identification of four phenolic compounds (Table 4). The most significant observation of this study is that the edafo-climatological conditions play a very substantial role in the phenolic profile of the olive oil. Although all samples came from the same cultivar, harvested at similar maturity and processed under the same conditions, the phenolic profile was quite different as demonstrated by HPLC-DAD quantification. Four phenolic compounds: Oleuropein, Hydroxytyrosol, Tyrosol, and Ligstrosid were identified by comparison of screening data with authentic standards. Indeed, the major detected secoiridoids is the oleuropein. A higher concentration was observed in WPO with $627.35 \mu \mathrm{g}$ g-1 for 2015 and $589.56 \mu \mathrm{g}$ g-1 for 2016, which were similar to those of COO. Such result confirms previous studies described by ref. 33. Other secoiridoids were identified at relatively low concentrations was the Ligstrosid. Its amount ranged from 5.27-5.89 $\mu \mathrm{g} \mathrm{g-1}$ for the WPO to 5.86-6.21 $\mu \mathrm{g} \mathrm{g-1}$ for the COO in the year of 2016 and 2015, respectively. The lowest concentration of the last component was recorded in UWPO (4.85-4.25 $\mu \mathrm{gg}-1)$ in the year of 2015 and 2016, respectively. Hydroxytyrosol and tyrosol were the major simple phenols, with WPO as the richest one reaching $26.41-27.32 \mu \mathrm{gg}-1$ and $1.61-0.95 \mu \mathrm{gg}-1$, respectively. These results are in agreement with those reported by several authors.14

This difference may be due to the geographical conditions. Significant differences between geographical areas were observed concerning secoiridoids amounts. 
The effects of the environment and pedo-climatic conditions on these compounds were clearly observed based on the diverse behaviors of each growing area.

\subsection{Oil Stability}

Oxidative stability is the chief parameter for guessing the olive oil quality and assessing the vulnerability of the oil to oxidative degeneration, which is affected by lipid composition and diverse antioxidant compounds, whose levels may be influenced by cultivar, year and place of production.34 The oxidative stability of the extra-virgin olive oils was measured as the induction time determined using the Rancimat method. The obtained results (Table 4) show that washing olive fruits clearly influenced oil stability in that the highest values were recorded for the WPO with $4.59 \mathrm{~h}$ in 2015 and 4.29 in 2016. These results are a little close to the results of those control olive oils (COO). The difference at the oxidative stability may be illustrated by the little difference from the levels of the content in phenolic compound. A good correlation has already been reported by other authors 31 between the oxidative stability and total phenolic content. In this context, Chtourou et al.,14 have shown that phenolic compounds contribution to oxidation stability is evident and when the phenolic and tocopherol content increased with the increase of the induction time.

\subsection{Tocopherols Composition}

Tocopherols are important analytical parameters thanks to their vitamin and nutritional properties and their role in protecting olive oil from free radicals. 35 Tocopherol analysis during the two consecutive crop years has revealed that climatic conditions have an impact on tocopherol content. Alpha-tocopherol, having vitamin properties, predominates over the other tocopherols in all studied olive oils. it is also influenced by the washing olive fruits. This concurs with other findings reported in the literature. 36 In fact, $\alpha$-Tocopherol content in WPO (315.25$340.28 \mathrm{mg} \mathrm{kg}-1$ ) was higher than that of UWPO (305.48 mg kg-1 (2015) and $309.78 \mathrm{mg} \mathrm{kg}-1$ (2016)). However, this content in both WPO and UWPO was lower than that of COO (Table 1). In this context, some research works37, 38 have shown that there are no differences in $\alpha$ Tocopherol composition with the change of season crop for the same cultivar of olive, while others 11 have found similar results as oils from other olive cultivars.

\subsection{Antioxidant Activity}

The IC50 values of the studied samples are listed in Table 1. UWPO have the lowest antioxidant activity for the crop season 2015 (91.32 mg mL-1). This ranking can be explicated through the correlation of antioxidant activity to polyphenols concentration and chemical structure, and hence to their free radical scavenging capacity and metal chelating properties.31 Differences in bioactive and antioxidant compounds between oils from the $\mathrm{PO}$ and $\mathrm{COO}$, as well as in antioxidant activity, were recorded. Moreover, differences were noticed comparing the analytical data of oils of the same field in the two consecutive years. A very low antioxidant activity was observed for the unwashed polluted olive oils (UWPO). In addition, our study showed a significant decrease $(p<0.05)$ in the antioxidant activity of the olive oils studied, which is consistent with the polyphenols profiles of the different oils. Thus, and according to Bulotta et al.,32 the most important antioxidants in olive oil are oleuropein aglycone and hydroxytyrosol. The decrease of the concentration in these two compounds during the 
ripening period may result in a decrease in the antioxidant activity. In fact, it became clear that antioxidant activity emanated from the synergistic effect of the several components of the oil. The latter's composition was influenced by the status of plant physiological status and fruit quality.39 Generally, air pollution caused a considerably higher metals accumulation of Polluted plants fruit surface, compared to Control plants fruits.19 In this case, it is probably because it is continuous and chronic, the multi-metal stress is considered harmful for fruits and the antioxidant capacity of olive was depressed.

\subsection{Metal Accumulation in Oil}

Interest in the occurrence of traces of heavy metals in oils and fats has increased notably in recent years. On the other hand, the detection and evaluation of environmental contamination of food materials by toxic heavy metals, such as $\mathrm{Fe}, \mathrm{Cu}, \mathrm{Cd}$, and $\mathrm{Zn}$, is becoming increasingly important. Metals are up taken in plants from soils, water, and air. The amounts of metals up taken are dependent on the genotype of the plant and geographic area. The results are summarized in Figure 1. Only $\mathrm{Cd}, \mathrm{Zn}, \mathrm{Cu}$, and Fe could be detected in the olive oils. Highest concentrations of all metals were recorded in non-washed fruits of olive trees surrounding the factory. Metal concentrations in oil samples were in almost all cases below the instrument detection limits of the international olive council.16 In this study, metals in UNPO were slightly higher than WPO. With regard to Fe concentration, UWPO oils of 2016 and 2015 contained $2.094 \mathrm{mg} \mathrm{kg}-1$ and $4.388 \mathrm{mg} \mathrm{kg}-1$, respectively, against $0.985 \mathrm{mg} \mathrm{kg}-1$ and $1.108 \mathrm{mg} \mathrm{kg}-1$, respectively, found in the WPO oils. Calculated fluxes of metals show that SIAPE could be a possible source of atmospheric pollution in the city. Together with natural metal sources, environmental pollution and agricultural habits (application of fertilizers or metal-containing pesticides) also play a role in the amounts of metals present in the olive tree and therefore, olive fruits, and olive oils.19, 40

\subsection{Chemometric Analysis}

A multivariate statistical analysis of the data set from the studied area was performed using PCA model including 53 selected variables among the analysis reported from different studied samples. These variables selection was justified by their major differences $(p=0.05)$ as well as their abundance in oils. Figure 2 exhibits the score plot (first [PC1] versus second [PC2] principal component) associated with the analyzed samples. The variance from this PCA was $77.16 \%$, of which $56.68 \%$ was attributable to PC1. The findings of this discriminative analysis were generally satisfactory. A map of samples (score plot) for the two principal components is shown in Figure $2 \mathrm{a}$, b. In fact, regarding the selected factors, oils from polluted and unpolluted areas could be gathered in three clusters. The first group comprised the two control olive oils samples COO 2015 and COO 2016, which was dominated after the varimax rotation by the followings variables: total phenols, tocopherols, squalene, pigments, oxidative stability, triglycerides, phenolic compounds, C18:2w6, C16:1w9, C17:1w8, C18:1w9, C18:3w3, C17:0, C20:1w9. The second group was characterized by unwashed polluted olive oils (UWPO 2015), which was dominated after the varimax rotation by the following variables: SOO, C18:2w6, Acidity, SOL, Peroxide value (PV), IC50, K232, and K270. Finally, the third group was composed of three samples WPO 2016, WPO 2015, and UWPO 2016. This group was found in a different quadrant of the plot, owing to their medium percentage in terms of C18:1w7, C20:0, C18:0, 
C24:0, C22:0, C16:1w7. The loading plot further explained this classification. The obtained results were affirmed by carrying out a Hierarchical Cluster Analysis dendrogram (HCA). In fact, Figure 2c shows three distinct clusters based on the threshold value (equal to 0.993431363), with a high similarity between WPO in 2015 and 2016. However, UWPO 2015 presented an extreme dissimilarity in comparison to the other samples. In this case, the formation of clusters and its linkage could be compared and linked to the groups formed in PCA (Figure $2 a, b)$. These conclusions are in good agreement with the results displayed in Tables 1-4.

\section{Conclusions}

In conclusion, this study revealed that the atmospheric pollution is responsible for the metals deposition on the epicarp of olive fruits with evidence of oil contamination. The oils derived from olives exposed to metals showed reduced antioxidant defenses, and their fatty acid, Squalene and triglyceride composition was disrupted. Furthermore, the aerial deposition of metals, even if it did not seem to pose a risk for oil safety, influenced the chemical quality of olive oils, thus negatively affecting their content in phenols, carotenoids, and chlorophyll. Moreover, oxidative stability was intensely worsened. Given that olive oil is a significant food product worldwide and that many productive olive orchards are exposed to numerous sources of pollution, the present research work could may contribute in the clarification of the processes and factors pertaining to the effects of atmospheric metal pollution on olive oil quality and its potential toxicity for humans. Actually, it demonstrated that the factor "washing olives" was a little efficient in improving the quality of polluted olives oils, yet it is not a solution. These findings must be taken into consideration when planning strategies for enhancing crop yield and oil quality under a Mediterranean climate, particularly in a producing and exporting country such as Tunisia.

\section{Acknowledgements}

The authors thank the Ministry of Higher Education Scientific Research (Laboratory LR14ES08), Tunisia, and ARIMNet 2 MedOOmics "Mediterranean Extra Virgin Olive Oil Omics: profiling and fingerprinting" - "Arimnet2/0001/2015" for the support of this research work. They are also grateful to Dr. Hazem Jabeur from the Sfax National Office of Olive Oil for their precious help with GC analyses for fatty acid and Triglycerids composition and, squalene and tocopherols contents. The authors would like to extend their thanks to Mrs. Leila Mahfoudhi, Teacher of English at the Sfax Faculty of Science, for proofreading and polishing the language of the manuscript.

\section{Conflict of Interest}

The authors declare no conflict of interest. 


\section{References}

1 N. Brophy, C. Dore, M. R. Hann, J. Jackson, K. King, T. P. Murrells, N. Passant, G. Thistlewaite, A. Wagner, Air Quality Pollutant Inventories for England, Scotland, Wales and Northern Ireland: 1990-2005, Report AEAT/ ENV; 2007.

2 I. Mezghani, N. Elloumi, F. B. Abdallah, M. Chaieb, M. Boukhris, Fluoride 2005, 38, 69.

3 F. Ben Abdallah, M. Boukhris, Pollut Atmospherique Fr 1990.

4 D. D. Ackerly, F. A. Bazzaz, Glob. Change Biol. 1995, 1, 199.

5 D. A. Grantz, J. H. B. Garner, D. W. Johnson, Environ. Int. 2003, 29, 213.

6 A. R. Wellburn, New Phytol. 1990, 115, 395.

7European Standard NF EN. Preparation of Methyl Ester of Fatty Acids. AFNOR. 2000.

8European Standard. NF EN ISO 5508-Animal and Vegetable Fats and Oils-Analysis by Gas Chromatography of Methyl Esters of Fatty Acids AFNOR. Paris, France. 1995.

9 A. Ben Mansour, B. Gargouri, E. Melliou, P. Magiatis, M. Bouaziz, J. Sci. Food Agric. 2016, 96, 4432.

10 D. Ollivier, J. Artaud, C. Pinatel, J. P. Durbec, M. Guérère, J. Agric. Food Chem. 2003, 51, 5723.

11 M. Issaoui, B. Mechri, A. Echbili, S. Dabbou, A. Yangui, H. Belguith, A. Trigui, M. Hammami, J. Food Lipids 2008, 15, 277.

12 R. Korifi, Y. Le Dréau, J. Molinet, J. Artaud, N. Dupuy, J. Raman Spectrosc. 2011, 42, 1540.

13European Standard. NF EN ISO 9936. Animal Vegetables Fats and Oils-Determination of Tocopherol and Tocotrienol Contents by High-Performance Liquid Chromatography. 2006.

14 M. Chtourou, B. Gargouri, H. Jaber, R. Abdelhedi, M. Bouaziz, Eur. J. Lipid Sci. Technol. 2013, $115,631$.

15 A. Ben Mansour, E. A. Porter, G. C. Kite, M. S. Simmonds, R. Abdelhedi, M. Bouaziz, J. Agric. Food Chem. 2015, 63, 1990.

16International Olive Council (IOC). Trade Standard Applying to Olive Oils and Olive Pomace Oils. COI/T, 15/NC No 3 Rev 7. Principe de Vergara, 154, 28002, Madrid, Spain. 2015.

17 B. Baccouri, W. Zarrouk, D. Krichene, I. Nouairi, N. B. Youssef, D. Daoud, M. Zarrouk, J Agron. 2007, 6, 388.

18 M.-N. Criado, M.-P. Romero, M. Casanovas, M.-J. Motilva, Food Chem. 2008, 110, 873.

19 R. Fourati, A. Scopa, C. B. Ahmed, F. B. Abdallah, R. Terzano, C. E. Gattullo, I. Allegretta, F. Galgano, M. C. Caruso, A. Sofo, Chemosphere 2017, 168, 514. 
20 S. B. Temime, E. Campeol, P. L. Cioni, D. Daoud, M. Zarrouk, Food Chem. 2006, 99, 315.

21 S. Laroussi-Mezghani, Y. Le Dréau, J. Molinet, M. Hammami, N. Grati-Kamoun, J. Artaud, Eur. Food Res. Technol. 2016, 242, 1087.

22 R. Mateos, M. M. Domínguez, J. L. Espartero, A. Cert, J. Agric. Food Chem. 2003, 51, 7170.

23 C. Samaniego-Sánchez, J. J. Quesada-Granados, H. L.-G. de la Serrana, M. C. López-Martínez, J. Food Compos. Anal. 2010, 23, 671.

24 A. Fernández-Cuesta, L. León, L. Velasco, R. De la Rosa, Food Res. Int. 2013, 54, 1885.

25 Z. Wiesman, Desert Olive Oil Cultivation: Advanced Bio Technologies, Academic Press, Elsevier, New York, NY, USA 2009.

26 S. Ammar, A. Zribi, A. Ben Mansour, M. Ayadi, R. Abdelhedi, M. Bouaziz, J. Oleo. Sci. 2014, 63.

27 B. Baccouri, S. B. Temime, W. Taamalli, D. Daoud, M. M'SALLEM, M. Zarrouk, J. Food Lipids 2007, 14, 19.

28 F. Aranda, S. Gomez-Alonso, R. R. Del Álamo, M. D. Salvador, G. Fregapane, Food Chem. 2004, 86, 485.

29 D. Ollivier, E. Boubault, C. Pinatel, S. Souillol, M. Guérère, J. Artaud, Annales des falsifications, de l'expertise chimique et toxicologique 2004, 965, 169.

30 B. Mechri, M. Issaoui, A. Echbili, H. Chehab, F. B. Mariem, M. Braham, M. Hammami, J. Hazard. Mater. 2009, 172, 1544.

31 S. Ben Brahim, H. Kelebek, S. Ammar, M. Abichou, M. Bouaziz, Food Chem. 2017, 229, 9.

32 S. Bulotta, M. Celano, S. M. Lepore, T. Montalcini, A. Pujia, D. Russo, J. Transl Med. 2014, 12,219

33 M. Servili, G. Montedoro, Eur. J. Lipid Sci. Technol. 2002, 104, 602.

34 D. Tura, C. Gigliotti, S. Pedò, O. Failla, D. Bassi, A. Serraiocco, Sci. Hortic. 2007, 112, 108.

35 E. Reboul, S. Thap, E. Perrot, M. J. Amiot, D. Lairon, P. Borel, Eur. J. Clin. Nutr. 2007, 61, 1167.

Crossref CAS PubMed Web of Science ${ }^{\circledR}$ Google ScholarServicio de Enlaces CSIC

36 S. Gharby, H. Harhar, H. El Monfalouti, B. Kartah, N. Maata, D. Guillaume, Z. Charrouf, J Nutr. Metab. 2012, 5, 31.

CrossrefGoogle ScholarServicio de Enlaces CSIC

37 M. D. Salvador, F. Aranda, S. Gomez-Alonso, G. Fregapane, Food Chem. 2003, 80, 359. 
38 M. Issaoui, S. Dabbou, B. Mechri, A. Nakbi, H. Chehab, M. Hammami, Eur. Food Res. Technol. 2011, 232, 867.

39 O. Rekik, A. Ben Mansour, M. Bouaziz, Electrophoresis 2017, 39.

40 E. J. Llorent-Martínez, M. L. Fernández de Cordova, P. Ortega-Barrales, A. Ruiz Medina, J. Am. Oil Chem. Soc. 2014, 91, 1823. 


\section{Figure captions}

Figure 1.- Metals extracted from olive fruits of control oils [CO] and polluted oils [PO]. The values represent means $[n=3] \pm S D$ of composite samples obtained from washed $[W]$ and unwashed [UW] fruits.

Figure 2.- a) Principal component analysis [PCA]: scatter plot of the studied samples. b) Principal component analysis applied to all samples considering 50 variables. Plot of component weights. c) Hierarchical cluster analysis [HCA]: dendrogram showing the clustering of the all analyses performed on oils from washed and unwashed polluted olives under two seasons 2015-2016 and 2016-2017. 
Table 1. Quality parameters of studied samples

\begin{tabular}{|c|c|c|c|c|c|c|}
\hline & 2015 & & 2016 & & $\mathrm{COO}$ & \\
\hline Samples & WPO & UWPO & WPO & UWPO & 2015 & 2016 \\
\hline Acidity [\%] & $0.21 \pm 0.00^{\mathrm{c}}$ & $0.3 \pm 0.01^{\mathrm{a}}$ & $0.13 \pm 0.00^{\mathrm{d}}$ & $0.24 \pm 0.00^{\mathrm{b}}$ & $0.1 \pm 0.00$ & $0.06 \pm 0.00^{\mathrm{f}}$ \\
\hline $\begin{array}{l}\text { Peroxide } \\
\text { value [meq } \\
\left.\mathrm{O}_{2} / \mathrm{kg}\right]\end{array}$ & $8.41 \pm 0.25^{\mathrm{c}}$ & $12.87 \pm 0.38^{\mathrm{a}}$ & $5.94 \pm 0.18^{\mathrm{d}}$ & $11.88 \pm 0.35^{\mathrm{b}}$ & $\begin{array}{l}2.02 \pm 0.0 \\
5^{\mathrm{e}}\end{array}$ & $1.01 \pm 0.03^{\mathrm{f}}$ \\
\hline$K_{232}$ & $2.83 \pm 0.08^{c}$ & $2.97 \pm 0.08^{\mathrm{a}}$ & $2.78 \pm 0.08^{\mathrm{a}}$ & $2.87 \pm 0.08^{\mathrm{a}}$ & $\begin{array}{l}1.97 \pm 0.0 \\
6^{\mathrm{b}}\end{array}$ & $1.87 \pm 0.05^{\mathrm{c}}$ \\
\hline$K_{270}$ & $0.19 \pm 0.00^{\mathrm{a}}$ & $0.24 \pm 0.01^{\mathrm{a}}$ & $0.21 \pm 0.01^{\mathrm{a}}$ & $0.22 \pm 0.01^{\mathrm{a}}$ & $\begin{array}{l}0.13 \pm 0.0 \\
0^{c}\end{array}$ & $0.14 \pm 0.00^{\mathrm{b}}$ \\
\hline $\begin{array}{l}\text { Carotenoids } \\
{\left[\mathrm{mg} \mathrm{Kg}^{-1}\right]}\end{array}$ & $4.15 \pm 0.09^{c}$ & $1.00 \pm 0.01^{\mathrm{e}}$ & $4.20 \pm 0.09^{b}$ & $3.90 \pm 0.08^{\mathrm{d}}$ & $\begin{array}{l}4.80 \pm 0.1 \\
\mathrm{a}\end{array}$ & $4.95 \pm 0.1^{\mathrm{a}}$ \\
\hline $\begin{array}{l}\text { Chlorophyll } \\
{\left[\mathrm{mg} \mathrm{Kg}^{-1}\right]}\end{array}$ & $9.13 \pm 0.44^{\mathrm{d}}$ & $3.58 \pm 0.17^{\mathrm{e}}$ & $12.6 \pm 0.61^{\mathrm{c}}$ & $8.48 \pm 0.41^{\mathrm{d}}$ & $\begin{array}{l}12.78 \pm 0 . \\
62^{\mathrm{b}}\end{array}$ & $16.96 \pm 0.82^{\mathrm{a}}$ \\
\hline $\begin{array}{l}\text { Total } \\
\text { Phenols } \\
{\left[\mathrm{mg} \mathrm{kg}^{-1}\right]}\end{array}$ & $162.00 \pm 3.24^{\mathrm{d}}$ & $116.00 \pm 2.32^{\mathrm{f}}$ & $170.00 \pm 3.40^{c}$ & $147.00 \pm 2.94^{\mathrm{e}}$ & $\begin{array}{l}353.00 \pm \\
7.06^{\mathrm{b}}\end{array}$ & $455.00 \pm 9.09^{\mathrm{a}}$ \\
\hline $\begin{array}{l}\mathrm{IC}_{50} \\
{\left[\mathrm{mg} \mathrm{mL}^{-1}\right]}\end{array}$ & $78.86 \pm 6.58^{\mathrm{a}}$ & $91.32 \pm 7.61^{\mathrm{a}}$ & $67.52 \pm 5.63^{\mathrm{a}}$ & $88.98 \pm 7.42^{\mathrm{a}}$ & $\begin{array}{l}44.76 \pm 3 . \\
73^{\mathrm{b}}\end{array}$ & $40.98 \pm 3.42^{b}$ \\
\hline $\begin{array}{l}\text { Oxidative } \\
\text { stability[h] }\end{array}$ & $4.56 \pm 0.17^{\mathrm{b}}$ & $1.11 \pm 0.04^{\mathrm{d}}$ & $4.29 \pm 0.16^{\mathrm{b}}$ & $3.59 \pm 0.14^{\mathrm{c}}$ & $\begin{array}{l}6.00 \pm 0.2 \\
3^{\mathrm{a}}\end{array}$ & $5.81 \pm 0.22^{\mathrm{a}}$ \\
\hline $\begin{array}{l}\alpha- \\
\text { Tocopherols } \\
{\left[\mathrm{mg} \mathrm{Kg}^{-1}\right]}\end{array}$ & $315.25 \pm 4.75^{\mathrm{c}}$ & $305.48 \pm 4.61^{\mathrm{e}}$ & $340.28 \pm 5.13^{c}$ & $309.78 \pm 4.67^{\mathrm{d}}$ & $\begin{array}{l}389.12 \pm \\
5.87^{\mathrm{b}}\end{array}$ & $396.47 \pm 5.98^{\mathrm{a}}$ \\
\hline $\begin{array}{l}\text { Squalene } \\
{\left[\mathrm{mg} \mathrm{kg}^{-1}\right]}\end{array}$ & $1123.39 \pm 16.13$ & $845.39 \pm 12.1$ & $1050.29 \pm 15$ & $985.21 \pm 14$ & $\begin{array}{l}1902.28 \pm \\
27.32^{\mathrm{a}}\end{array}$ & $1862.01 \pm 26.74^{\mathrm{a}}$ \\
\hline
\end{tabular}

Each value represents the mean of three determinations $[n=3] \pm$ standard deviation. a-fDifferent letters in the same line concerning all samples of olive oil fruits indicating significantly different values $[p<0.05]$. 
Table 2. Fatty acid compositions [\%] of studied samples

\section{$20152016 \quad$ COO}

\section{Fatty acid composition [\%] WPO $\quad$ UWPO $\quad$ WPO $\quad$ UWPO $2015 \quad 2016$}

\begin{tabular}{|c|c|c|c|c|c|c|}
\hline C16:0 & 1.8 & $19.90 \pm 0.78^{a}$ & $20.50 \pm 0.81^{\circ}$ & $20.35 \pm 0.80$ & $13.30 \pm 0.52^{b}$ & $12.96 \pm 0.51^{b}$ \\
\hline C16:1w9 & $0.07 \pm 0.00^{f}$ & $0.05 \pm 0.00^{\mathrm{e}}$ & $0.07 \pm 0.00^{\mathrm{d}}$ & $0.09 \pm 0.00^{\mathrm{c}}$ & $0.12 \pm 0.00^{\mathrm{b}}$ & $0.13 \pm 0.00^{\mathrm{a}}$ \\
\hline C16:1w7 & $2.33 \pm 0.09^{\mathrm{b}}$ & $2.70 \pm 0.11^{\mathrm{a}}$ & $2.87 \pm 0.11^{\mathrm{a}}$ & $2.92 \pm 0.11^{\mathrm{a}}$ & $1.33 \pm 0.05^{\mathrm{c}}$ & $1.29 \pm 0.05^{\mathrm{d}}$ \\
\hline C17:0 & $0.02 \pm 0.00^{\mathrm{e}}$ & $0.04 \pm 0.00^{\mathrm{f}}$ & $0.06 \pm 0.00^{\mathrm{d}}$ & $0.06 \pm 0.00^{\mathrm{c}}$ & $0.08 \pm 0.00^{\mathrm{a}}$ & $0.04 \pm 0.00^{\mathrm{b}}$ \\
\hline C17:1w8 & $0.11 \pm 0.00^{\mathrm{c}}$ & $0.03 \pm 0.00^{\mathrm{f}}$ & $0.07 \pm 0.00^{\mathrm{e}}$ & $0.05 \pm 0.00^{\mathrm{d}}$ & $0.15 \pm 0.00^{\mathrm{b}}$ & $0.17 \pm 0.00^{\mathrm{a}}$ \\
\hline C18:0 & $2.23 \pm 0.09^{\mathrm{a}}$ & $2.08 \pm 0.08^{\mathrm{a}}$ & $2.18 \pm 0.09^{\mathrm{a}}$ & $2.13 \pm 0.08^{\mathrm{a}}$ & $2.05 \pm 0.08^{\mathrm{a}}$ & $2.06 \pm 0.08^{\mathrm{a}}$ \\
\hline C18:1w9 & $56.56 \pm 2.22^{\mathrm{a}}$ & $50.15 \pm 1.97^{\mathrm{a}}$ & $52.07 \pm 2.05^{\circ}$ & $50.47 \pm 1.98$ & $59.46 \pm 2.33^{\mathrm{a}}$ & $60.22 \pm 2.37^{\mathrm{a}}$ \\
\hline $18: 1 w 7$ & $2.31 \pm 0.09^{\mathrm{b}}$ & $3.90 \pm 0.15^{\mathrm{a}}$ & $2.97 \pm 0.12^{\mathrm{a}}$ & $3.56 \pm 0.14^{\mathrm{a}}$ & $2.45 \pm 0.10^{\mathrm{b}}$ & $2.28 \pm 0.09^{\mathrm{b}}$ \\
\hline
\end{tabular}

SFA, saturated fatty acids; MUFA, monounsaturated fatty acids; PUFA, polyunsaturated fatty acids; UFA, unsaturated fatty acids. Each value represents the mean of three determinations [ $n=3$ ]. a-fDifferent letters in the same line concerning all samples of olive oil Fruits indicating significantly different values [ $<<0.05]$. 
Table 3. Triglyceride composition [\%] of studied samples

2015

2016

\section{COO}

Triglyceride composition [\%] WPO

UNPO WPO

UNPO

2015

2016

$\begin{array}{lllllll}\text { LLL } & 0.79 \pm 0.04^{\mathrm{c}} & 0.78 \pm 0.04^{\mathrm{c}} & 0.89 \pm 0.04^{\mathrm{b}} & 0.81 \pm 0.04^{\mathrm{b}} & 0.65 \pm 0.03^{\mathrm{b}} & 0.90 \pm 0.03^{\mathrm{a}} \\ \text { PLLn } & 0.70 \pm 0.04^{\mathrm{a}} & 0.65 \pm 0.03^{\mathrm{b}} & 0.83 \pm 0.04^{\mathrm{a}} & 0.80 \pm 0.04^{\mathrm{a}} & 0.68 \pm 0.03^{\mathrm{a}} & 0.50 \pm 0.02^{\mathrm{a}} \\ \text { OLLn+PoLL } & 0.30 \pm 0.01^{\mathrm{c}} & 0.25 \pm 0.01^{\mathrm{e}} & 0.21 \pm 0.00^{\mathrm{d}} & 0.34 \pm 0.01^{\mathrm{c}} & 0.30 \pm 0.01^{\mathrm{a}} & 0.21 \pm 0.00^{\mathrm{b}} \\ \text { OLL } & 5.02 \pm 0.23^{\mathrm{b}} & 5.00 \pm 0.23^{\mathrm{b}} & 6.12 \pm 0.28^{\mathrm{a}} & 6.26 \pm 0.28^{\mathrm{a}} & 6.35 \pm 0.29^{\mathrm{a}} & 6.40 \pm 0.29^{\mathrm{b}} \\ \text { OOLn } & 2.02 \pm 0.09^{\mathrm{a}} & 2.01 \pm 0.09^{\mathrm{b}} & 1.89 \pm 0.09^{\mathrm{b}} & 1.97 \pm 0.09^{\mathrm{b}} & 1.99 \pm 0.09^{\mathrm{a}} & 1.98 \pm 0.09^{\mathrm{a}} \\ \text { PLL } & 4.11 \pm 0.19^{\mathrm{b}} & 3.72 \pm 0.17^{\mathrm{b}} & 2.94 \pm 0.13^{\mathrm{c}} & 3.54 \pm 0.16^{\mathrm{c}} & 3.50 \pm 0.16^{\mathrm{a}} & 2.1 \pm 0.10^{\mathrm{b}} \\ \text { POLn } & 1.50 \pm 0.07^{\mathrm{a}} & 1.38 \pm 0.05^{\mathrm{b}} & 1.03 \pm 0.05^{\mathrm{b}} & 1.35 \pm 0.06^{\mathrm{b}} & 1.47 \pm 0.07^{\mathrm{a}} & 1.52 \pm 0.07^{\mathrm{a}} \\ \text { LOO+PLnP } & 12.99 \pm 0.60^{\mathrm{b}} & 15.36 \pm 0.71^{\mathrm{b}} & 16.57 \pm 0.76^{\mathrm{b}} & 16.45 \pm 0.76^{\mathrm{b}} & 16.63 \pm 0.77^{\mathrm{a}} & 16.59 \pm 0.76^{\mathrm{a}} \\ \text { PoOO } & 2.78 \pm 0.13^{\mathrm{a}} & 2.64 \pm 0.12^{\mathrm{b}} & 2.10 \pm 0.10^{\mathrm{d}} & 2.50 \pm 0.11^{\mathrm{c}} & 1.58 \pm 0.07^{\mathrm{d}} & 2.70 \pm\end{array}$

$P$, palmitic; S, stearic; O, oleic; L, linoleic, Po, palmitoleic, Ln, linolenic; A, Arachidic. ECN42 = LLL + OLLn + PoLL $+P L L n . E C N 44=O L L+O O L n+P L L+P O L n . E C N 46=O O L+L n P P$ $+P L O+P P L+S L L+P O O P . E C N 48=O O O+O O P+P O P . E C N 50=S O O+P O S$. Each value represents the mean of three determinations $[n=3] \pm$ standard deviation. $a-f D i f f e r e n t$ letters in the same line concerning all samples of olive oil Fruits indicating significantly different values $[p<0.05]$. 
Table 4. Quantification of the major identified phenolic $[\mu \mathrm{g} / \mathrm{g}]$ of studied samples

$$
2016
$$

2015

UWPO

\section{WPO}

\section{UWPO}

COO

Compounds $\left[\mu \mathrm{g} \mathrm{g}^{-1}\right]$ WPO

$14.62 \pm 0.29^{\mathrm{c}}$

$27.32 \pm 0.54^{\mathrm{b}}$

2015

Hydroxytyrosol

$26.41 \pm 0.53^{\mathrm{b}}$

n.d

$0.95 \pm 0.02^{\mathrm{e}}$

$15.21 \pm 0.30^{\circ}$

$30.54 \pm 0.61^{\mathrm{a}}$

$30.26 \pm 0.6^{\mathrm{a}}$

Tyrosol

$1.61 \pm 0.03^{\mathrm{c}}$

$589.56 \pm 11.81^{\mathrm{b}}$

$1.02 \pm 0.02^{\mathrm{d}} \quad 1.82 \pm 0.04^{\mathrm{b}}$

$2.05 \pm 0.04^{\mathrm{a}}$

Oleuropein derivatives $627.35 \pm 12.57^{\mathrm{a}} 484.75 \pm 9.71^{\mathrm{c}}$

Ligstrosid derivatives

$5.27 \pm 0.10^{\circ}$

$4.85 \pm 0.09^{\mathrm{c}}$

$5.89 \pm 0.12^{\mathrm{a}}$

$4.25 \pm 0.08^{\mathrm{d}} \quad 5.86 \pm 0.27^{\mathrm{a}}$

$6.21 \pm 0.12^{\mathrm{a}}$

Total

$$
660.64 \pm 13.23^{\mathrm{a}} 504.22 \pm 10.10^{\mathrm{b}} 623.72 \pm 12.50^{\mathrm{a}} 412.33 \pm 8.26^{\mathrm{c}} 698.42 \pm 14.00^{\mathrm{a}} 678.77 \pm 13.60^{\mathrm{a}}
$$

Each value represents the mean of three determinations $[n=3] . a-f$ Different letters in the same line concerning all samples of olive oil Fruits indicating significantly different values $[p<0.05]$. 
Figure 1

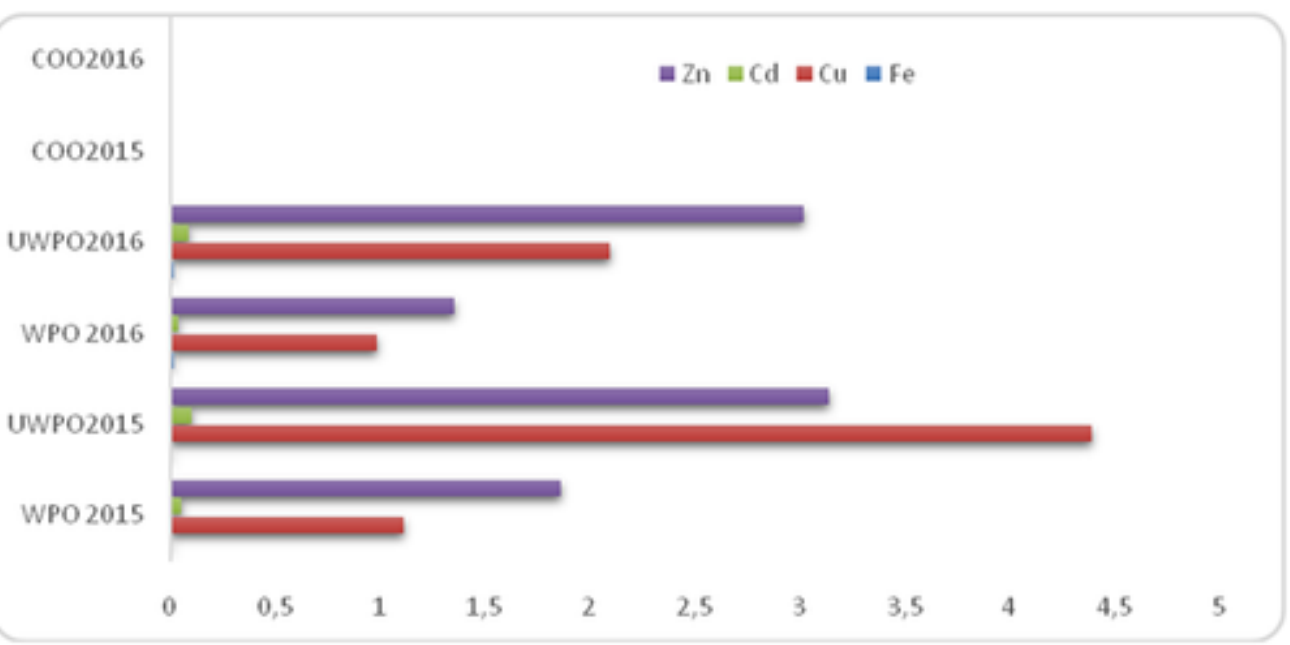


a

Observations (axes F1 et F2 : 77,16\%)

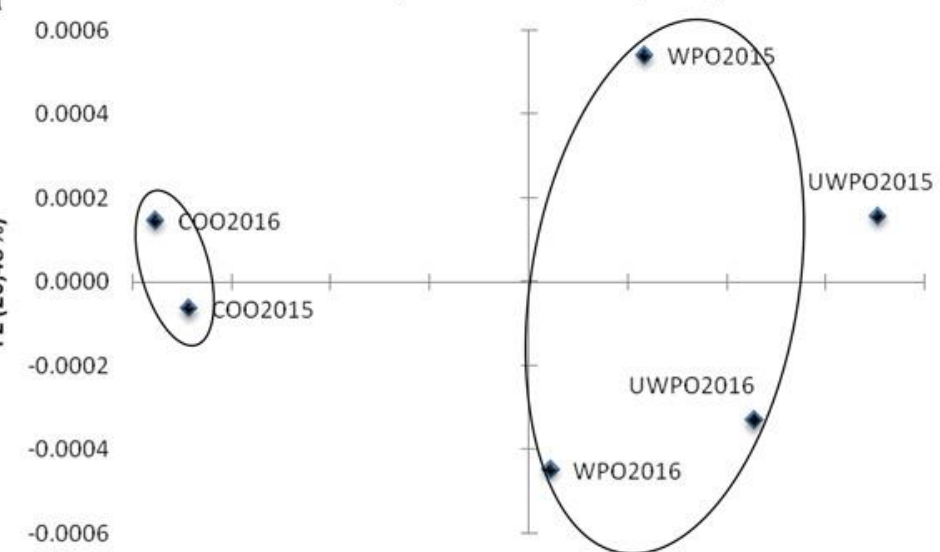

$\begin{array}{lllllllll}-0.0008 & -0.0006 & -0.0004 & -0.0002 & 0.0000 & 0.0002 & 0.0004 & 0.0006 & 0.0008\end{array}$

F1 $(56,68 \%)$

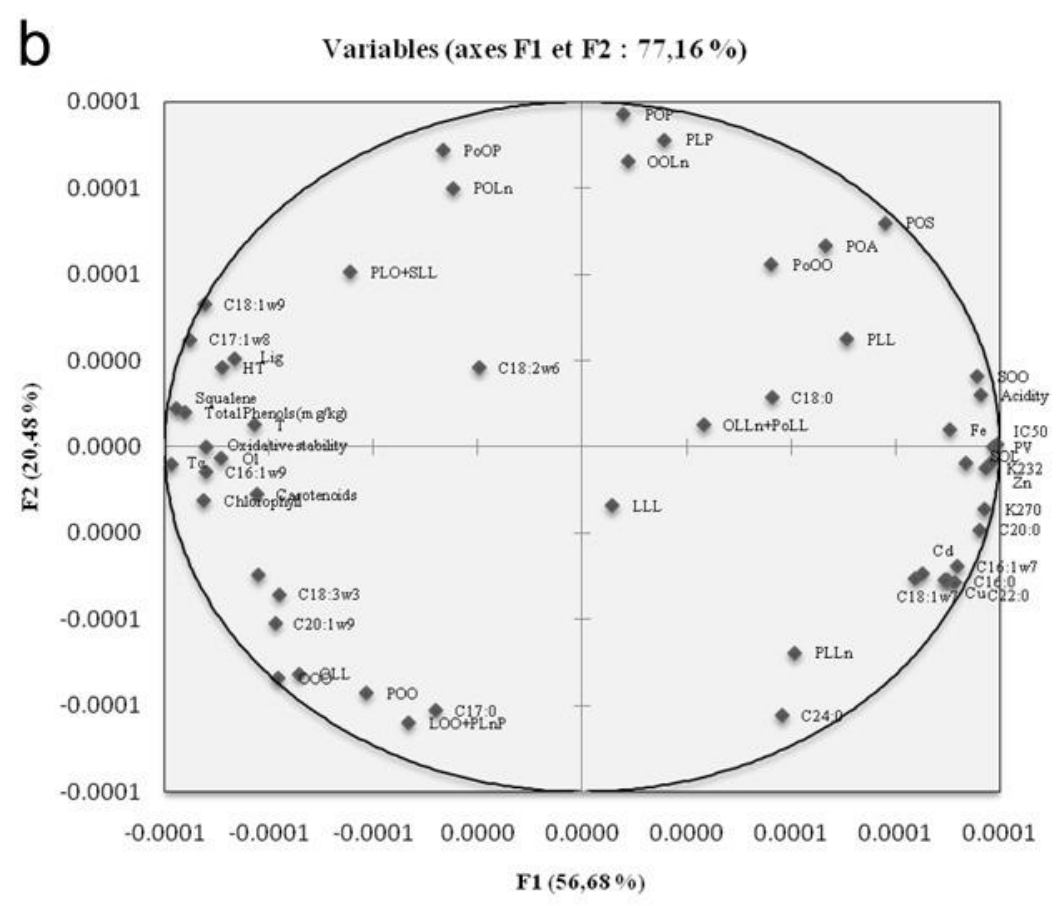

C Dendrogram

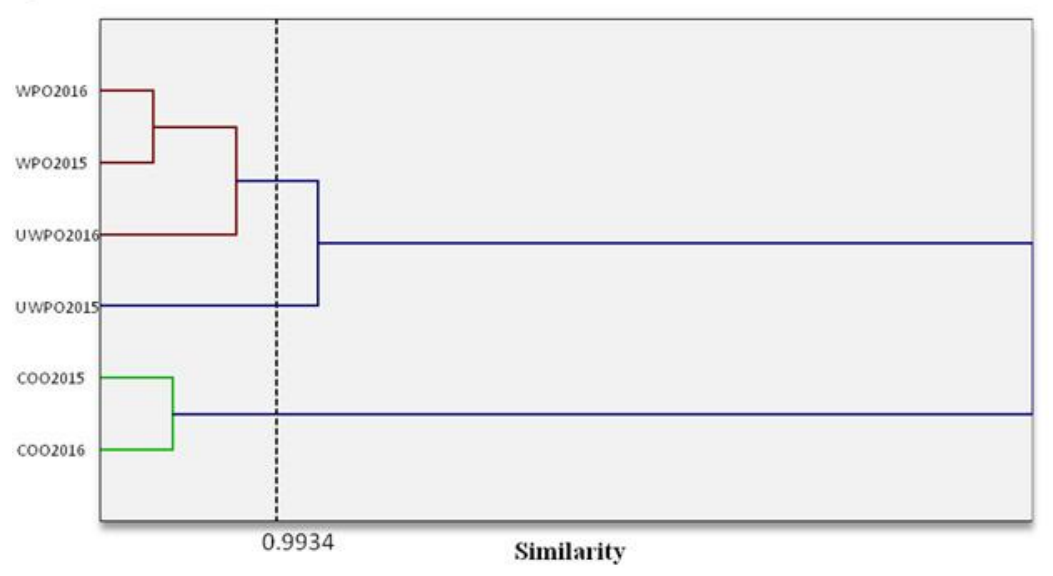


